\title{
Technoscience Art: A Bridge Between Neuroesthetics and Art History?
}

\author{
Alkım Almıla Akdăg Salah \\ UCLA, Dept. of Art History \\ Los Angeles, US
}

\author{
Albert Ali Salah \\ CWI, Signals and Images \\ Amsterdam, The Netherlands
}

\begin{abstract}
One of the recent and exciting developments in mainstream art history is its confrontation with the cognitive sciences and neurology. This study is based on the problems these disciplines face before they can contribute to each other. We inspect several critical issues resulting from this encounter, especially in the context of the recently developing field of neuroesthetics. We argue that it is the language barrier between the disciplines, rather than any fundamental conceptual divison, that causes the lack of understanding on both sides. Shared terms in arts and neuroscience are elusive, and the different connotations of extant terms in these separate disciplines must be addressed. We propose technoscience art as a ground where joint terminology may be developed, an audience familiar to the concerns of both sides can be formed, and a new generation of scientifically-knowledgeable artists and scientists can interact for their mutual benefit.
\end{abstract}

The aim of art history is to analyze artistic expression, contexts, production and consumption of arts from a historical perspective. Much of art history deals with the visual arts, and for some influential art historians the psychology of vision has been an essential critical tool. Yet for the last decade, art history has been lagging behind the current research on vision, cognitive science and neuroscience. On the other hand, aesthetics has been an important area of study for psychologists since Fechner ${ }^{1}$, and the neural correlates of aesthetic feelings have recently been explored. This paper investigates the two-way interaction between brain research and art history, identifying their common questions and taking on the important methodological issues that prevent more fruitful collaboration between these disciplines.

The interaction between brain research and art history is valuable for art historians, artists, and neuroscientists all alike. Does it help to understand the mechanisms of a visual phenomenon to evaluate it in the context of an artwork? If the answer is affirmative, then the contribution of neurology to art history should be obvious. Zeki, for example, emphasizes that many of the visual phenomena attributed to the eye actually occur in the cortex (Zeki \& Lamb, 1994). Traditionally, what the artist achieves by directing technical skills with guidance of intuition and honed artistic judgement can only be evaluated by an equally developed artistic judgement. This persuasion led to the birth of specializations like art historians, critics, and connoisseurs. Yet there is an undeniable search for quantification and more objective venues of evaluation, to which neuroscience is a very promising path. Similarly, the production of a new artwork sometimes involves creation of unique experiences for the audience, and artists would benefit from a thorough understanding of perceptual mechanisms. This is particularly true in the case of technoscience art which more often than not combines several perceptual modalities and in which crossmodal perceptual influences are significant. ${ }^{2}$. From the scientific side, to use Eric Kandel's words “it is clear what the gain would be for neural science. From a biological point of view, one of the ultimate challenges is to understand the perceptual processing by the brain of conscious experience and emotion" (Kandel \& Mack, 2003).

The recently developing field of neuroesthetics seeks the neural correlates of artistic judgement and artistic creation. Yet the concept of 'art' does not have a universally accepted and stable definition. The language barrier between art theory and neurology further complicates this issue, and there is a pressing need for some common ground.

\section{Neuroesthetics}

As its name implies, neuroesthetics is an attempt to combine neurological research with aesthetics by investigating the experience of beauty and appreciation of art on the level of brain functions and mental states. The first publications on the topic were authored by prominent neuroscientists (Changeux, 1994; Zeki, 1999). Although its methodology and research questions suggest that neuroesthetics should be a sub-discipline of neuroscience, today the topic attracts scholars from other disciplines as well, including aestheticians and art historians. These scholars either collaborate with neuroesthetics researchers, or apply neuroesthetics in their own research. Especially after the foundation of the Institute of Neuroesthetics through the collaboration of the London School of Neurology and University of California,

\footnotetext{
${ }^{1}$ For an account of experimental aesthetics in the domain of psychology see (Silvia, 2005).

${ }^{2}$ Two perceptual events in different modalities can interact in non-trivial ways, leading to modification of the sensation in one modality, or even to the creation of a novel sensation. An example is the famous McGurk effect, where a persons image mouthing the syllable "ga" and the accompanying audio signal of the spoken syllable "ba" produce the sensation of the syllable "da". For a review of how visual sensation interacts with other sensory modalities see (Spence \& Driver, 2004).
} 
Berkeley, the interest in neuroesthetics has grown. Conferences held on the topic attract linguists, literary critics, musicologists and cognitive scientists, but the agenda of neuroesthetics is set mostly by neuroscientists. We distinguish between three different approaches followed in the field.

The first approach relies on observation of subjects viewing art samples and inspection of the mechanism of vision, with the aim of inducing general rules about aesthetics. This is the most popular approach to neuroesthetics, and is championed by its godfather Semir Zeki in his book Inner Vision: An Exploration of Art and the Brain (Zeki, 1999). This study has reached a wide audience through its 'plain' language and non-technical argumentation and has attracted the attention of many art historians. In this book, Zeki focuses on famous modern artworks and artists, comparing the theoretical arguments and styles used by these artists with the latest findings in vision research. He argues that while viewing modern artworks, neurons that respond to visual primitives are consistently activated, naturally leading to pleasing sensations. For instance the horizontal and vertical lines in the paintings of Mondrian and the movement patterns in the kinetic sculptures of Calder are both perceived early in the human visual system, as there are groups of neurons responding to these primitive stimuli. Based on these findings, Zeki also suggests that artists -in some mysterious way- have some insight into the structure of the brain.

Another widely-read but controversial paper along these lines comes from Ramachandran and Hirstein (1999). In "The Science of Art," they put forward eight universal rules for aesthetics. These rules were based on earlier research in psychology, ethology, and Gestalt theory. Some of them are known to artists either intuitively or explicitly for hundreds of years, and Gestalt theorists like Arnheim have already emphasized the importance of these 'laws' thirty years before Ramachandran (Arnheim, 1969). However, according to Ramachandran and Hirstein, specifying the rules is only a part of the big question. In addition to this specification, we must understand why these rules came into being instead of others (i.e. the "evolutionary rationale") and we must also discern which neurological mechanisms are involved in the realization of these rules. Only then will it be possible to grasp how this complex outcome of human nature we call "art" is created (Ramachandran \& Hirstein, 1999).

The second approach aims at establishing the link between certain brain areas and artistic activity. The followers of this approach either study artists with neural problems, discerning between their output before and after the onset of the problem, or inspect the works of artistic savants, whose brain activation is unusually high in certain areas of the brain. Especially cases with known and well documented brain damage provide particular insight into neural mechanisms of artistic creation. Mario Mendez, for example, explores the stylistic changes in the works of artists with frontotemporal dementia (FTD) (Mendez, 2004). Patients with damage to the left hemisphere have demonstrated an expansion in the artistic (and more visual) abilities of the intact right hemisphere, while FTD patients with predominant right temporal involvement had difficulties in grasping artistically essential primitives. Through an analysis of the work of these patients Mendez concludes that 'the extraction and exaggeration of the essence of art' both reside at the right hemisphere ${ }^{3}$.

In contrast to approaches focusing on the artistic abilities and creativity, the third approach investigates aesthetic enjoyment through brain-imaging experiments on subjects looking at pictures. An example of this approach is the experiment conducted by Hideaki Kawabata and Semir Zeki (Kawabata \& Zeki, 2004), in which the question is whether specific brain areas are activated when subjects are confronted with pictures that are deemed beautiful or ugly. The criteria for being beautiful or being ugly are not specified by the experimental setup, and the subjects were asked to choose neutral, beautiful, and ugly images from a database. Then they were shown these images whilst in the fMRI scanner. For each category (portrait, landscape, still life, and abstract compositions), specialized activation areas were found; for instance the fusiform gyrus predictably responded to portraits. But for the perception of beautiful and ugly, no special area was singled out. Instead, the experiment revealed increased activation of orbito-frontal cortex (known to be responsive to rewarding stimuli (Rolls, 2000)) for beautiful images, and increased activation of the motor cortex for both ugly and beautiful images. Based on these results, the authors argue that the sense of beauty and aesthetic judgement presuppose a change in the activation of the brain's reward system.

A fundamental methodological crux for all these approaches is whether the aesthetic judgements are perceived as bottom-up processes driven by neural primitives or as topdown processes with high-level correlates. Zeki's approach initially tended towards the bottom-up, but changed as he continued to develop his theory of aesthetics based on neurological findings. In one of his early papers on the subject, Zeki relates the modern artistic tendency to single out and emphasize a certain visual primitive in an artwork (e.g. a certain colour, simple motions, geometric shapes and compositions) to the strength of bottom-up activation created by this intensified stimulus (Zeki \& Lamb, 1994). According to Zeki, what the kinetic artist does when he or she reduces the visual stimulus to pure motion is to act upon an unvoiced intuition about the dynamics of the brain.

While this perspective may sound plausible for some modern art pieces, it is certainly not powerful enough to encompass most of aesthetic experience. The difficulty that needs to be breached is the huge gap between the primitives and high-level concepts, which requires operating in several resolutions at the same time. While the primitives have been explored by neurologists with success, most of the high-level concepts have been in the domain of philosophy for hundreds of years. Inevitably, Zeki saw the need for objective descriptions of more abstract concepts, and high-level notions like "beauty" are probed for neural correlates in his later papers on neuroesthetics, as mentioned. He also arrived at an ex-

\footnotetext{
${ }^{3}$ For other examples of this approach see (Bentivoglio, 2003; Bogousslavsky, 2003; Otte, De Bondt, Wiele, Audenaert, \& Dierckx, 2003; Ravin \& Ravin, 1999; Sahlas, 2003; Stewart, 2002).
} 
planation of art as a by-product of a more general conceptformation and abstraction function of the brain (Zeki, 2004).

In his article "Neural Concept Formation and Art: Dante, Michelangelo, Wagner," Zeki challenges some of the most influential philosophical notions, including Kant's claim that space and time are the fundamental a-priori forms (Zeki, 2004). He reminds us that our perceptions rely on different mechanisms that operate in different spatial and temporal resolutions. Colour and motion are processed by different brain areas, and are perceived with different speeds. Furthermore, it has been amply demonstrated that very similar sensory inputs can produce different perceptions under slightly different conditions, indeed, many visual illusions are based on this fact. Instead, he proposes that the basic mechanism of the brain is that of neural abstraction. To give an example, a neuron in the primary cortex area that responds selectively to a certain stimulus, like a straight line with a specific orientation, is interpreted as abstracting this information. This ability of selective processing, when applied to the whole brain, and to all levels of processing, is powerful enough to lead to concept formation.

But what happens when we view an object? Even though we arrive at the idea of an object through abstraction, our experience "remains that of the particular, and the particular that we experience may not always satisfy the Idea formed in and by our brains" (Zeki, 2004). Thus, there is a difference between the particular we experience and the idea of it formed in our brain from all previous experiences with particulars of the same kind. According to Zeki, art comes into being through the conflict between the particular and the idea: "A refuge lies in recreating the brain's ideal in art and through art... The translation of concepts in the artist's mind onto canvas, or into music or literature constitutes art. Great art is that which corresponds to as many different concepts in as many different brains over as long a period of time as possible. Ambiguity is such a prized characteristic of all great art because it can correspond to many different concepts." (Zeki, 2004).

We should note that here, Zeki refers to the famous cave analogy of Plato where only the shadows (i.e. particulars) of the real object (i.e. the Idea) are accessible to the dwellers of the cave. The relation between the particular and the Ideal is one of the core questions of philosophy, one that has been particularly important to aesthetics and art history. According to Plato, artistic expression, which relies on the imperfect collection of the Ideas through particulars, is a mere imitation of an insufficient copy. It was Kant who salvaged aesthetic judgements (and thus, art) from this inferior status by rendering it as a bridge between pure and practical reason. ${ }^{4}$ In Zeki's argument Kant's a priori notions of time and space are replaced with a faculty of abstraction that commences at the neural level, but the path from input-selective neurons to concept-selective neural structures is only postulated in very rough terms. When the difference in the level of abstraction is so great, the primitives lose much of their significance, unless they can be consistently and productively linked to concepts. In the case of aesthetics and the search for its neural correlates, we observe that so far this link has been insuffi- ciently explored.

Present neuroscientific experimental approaches share another shortcoming. The evaluation of aesthetic judgements through neuroloscience is mostly confined to visual stimuli, for which the methodology is most familiar and most advanced. ${ }^{5}$ Yet aesthetic judgements exist in all domains: the sensation perceived by a painter in front of a beautiful picture is very similar to the sensation perceived by a mathematician reading an elegant proof. A true understanding of aesthetic judgements can only be achieved by dissociating it from purely visual stimulus, and searching for its correlates across many domains. Officially-designated art is not, after all, the only thing that provokes aesthetic responses. Subsequently, new experimental designs are necessary to take into account different manifestations of aesthetic experience.

\section{From the Perspective of Art History}

The Greek philosophers and the Church fathers have already carefully distinguished between things perceived and things known. It is entirely evident that they did not equate things known with things of sense, since they honored with this name things also removed from sense (therefore images). Therefore, things known are to be known by the superior faculty as the object of logic; things perceived [are to be known by the inferior faculty, as the object] of the science of perception, or aesthetic. (Baumgarten, 1954) ${ }^{6}$

Sensations in perceptual experience are not chaotically perceived. Rather they are ordered. There must be some form that determines this order of perceptual experience. It is this form that is the object of aesthetics. (Wessell Jr, 1972)

All perceiving is also thinking, all reasoning is also intuition, all observation is also invention. (Arnheim, 1956)

According to Rudolf Arnheim, the distinction between perceiving and thinking is arbitrary, since all mental capacities function as a whole (Arnheim, 1969). Perceiving itself asks for an active and immediate interpretation, as well as a reasoning process. Without making a distinction between objects, contours, colors, and movement on the level of neural activity, we cannot decipher what we 'perceive,' or better put, what we 'see.' Most of the sense data are filtered out in

\footnotetext{
${ }^{4}$ For Kant, aesthetic judgements were primarily about nature, not art. Nevertheless his theories were of utmost importance in the history of aesthetics and art history, and are applied for artworks as well (Hammermeister, 2002).

${ }^{5}$ Other areas where aesthetic judgements are put under neurological investigations are music, dance and theatre (Seeley, 2006).

${ }^{6}$ For the importance of Baumgarten in the history of aesthetics see (Wessell Jr, 1972), for a negative reading of Baumgarten in the history of philosophy see (Dixon, 1995).
} 
early stages of neural processing, and only the necessary information is used to construct a perception of the otherwise overwhelming visual stimuli. That means we 'think' while we 'see.'

Arnheim established his theory, which is four decades old now, by experimenting with basic geometrical forms and their effects on human psychology. Today, several aspects of this theory are validated with recent advances in neuroscience (like the discovery of mirror neurons), and with contributions of scholars from different disciplines who show the vitality of images in thinking (Stafford, 2004; Lakoff, 2006). Arnheim's important contribution is to show that the age-old dichotomy between seeing and thinking should no longer be considered as trivially true. Seeing has been associated with aesthetic experience and emotions, whereas the usage of the language has been associated with conceptual thinking and reasoning. In order to 'reason,' one needs words, and the boundaries of language set the boundaries of thought. This belief in the superiority of verbal communication as opposed to the visual had an influence in almost all domains of everyday life, including scientific practice.

The polarization between the intellect (faculties of reasoning, understanding, acquisition of truth) and the senses (percepts, feelings, emotions) is a deeply ingrained distinction in Western thought. For long, there was a tacit understanding of a preference of one domain over the other: cognition was held to be superior to perception. When Baumgarten coined the term aesthetics as the science of perception, he effectively institutionalized this polarization. However, since art history was primarily occupied with theories of aesthetics, and dealt mainly with visual (perceptual) stimuli, it has struggled to by-pass this differentiation. We could say that in the end, the discipline has achieved a discourse that effaced this polarization by going through various transformations.

Contemporary art production and criticism do not essentialize the aesthetic dimension for artworks; the visual aspects of the works are not on equal footing with their conceptual dimension anymore. Art is discussed in terms of a direct association with cultural patterns and cognitive faculties, and its importance in terms of its capacity to arouse deep perceptual or emotive responses has been de-emphasized. As David Freedberg notes (Freedberg \& Gallese, 2007), late $20^{\text {th }}$ century art history prefers to disregard the element of emotion in its theories of aesthetics. Today, this disownment of emotion is so ingrained into the discipline that most of the contemporary artworks are approached with little attention to their emotional potential. The goals of the artist and cultural contexts of the work have become much more important than the aesthetic dimension of the artwork. ${ }^{7}$

The triumph of conceptual interpretation over perceptual and emotional response is the outcome of an agenda that has its roots in the early $20^{\text {th }}$ century. David Freedberg and Vittorio Gallese mark its first strong expression to the publication of R.G. Collingwood's The Principles of Art, which differentiated between the emotive and cognitive aspects of art, disregarding the former in favour of the latter and equating art with language (Freedberg \& Gallese, 2007). Today, this view has thoroughly permeated into the mainstream art history, and many art historians regard art as a text that is only meaningful when it is in the right context, i.e. when it is interpreted in connection with its relation to the intentions, thoughts, and culture of its maker. For example, Noell Carroll and Arthur Danto both argue that artworks affect the viewers not on the premises of visual stimuli, but on the historical knowledge they are based: the audience cannot see a work of art without relating it to some knowledge of art history (Carroll, 1986; Danto, 2001). ${ }^{8}$ Art history thus defines its agenda as a search for the particulars in the specifics of technique, artistic heritage, and cultural context. This perspective is directly in opposition with the universalist and reductionist search for neural correlates of aesthetic judgement. ${ }^{9}$ This opposition is bolstered by a misconception on the side of the art historian about the interpretation of neurological findings, a belief that a neural basis of aesthetics would preclude individual variation. Consequently, any interpretation that draws on the neurology of aesthetic judgements must carefully weigh the importance of the cultural aspects of artistic experience against the physical constraints and principles that are derived from an understanding of brain functions, in order to be accepted by art historians.

This point is nowhere as clearly illustrated as in Ramachandran's bold statement on 'cubism' (Ramachandran, 2001). According to Ramachandran, certain art forms are necessarily aesthetically pleasing, because they are composed of visual primitives like uniform colours, symmetry, lines and corners that activate lower tiers of the visual system strongly. For him, it is a consequence of the wiring of our brains that we like Picasso's cubist works, and any statement to the contrary is due to misguided cultural suppression. This kind of reductionism is anathema to art history, as it greatly downplays the cultural, personal and conceptual dimensions of artistic enjoyment. Ramachandran's approach is also very superficial about historical specifics and consequently does not find much support among art historians. If cubism is necessarily pleasing, they ask, then why was it ridiculed when it first appeared? And why was its period of popularity as a technique of painting so brief?

For many art historians, neuroesthetics is too reductive to offer anything to art history. There are, however, a few scholars that would like to re-assert the relevance of perception and aesthetics in the interpretation of artworks (Rollins,

\footnotetext{
${ }^{7}$ For the relation of aesthetics to emotions see (Cupchik, 1994).

${ }^{8}$ Thirty years after Collingwood, this perspective was firmly established by the publication of Nelson Goodman's Language and Art. In this influential book, Goodman compared the content of pictures with narratives and called them "language-like artificial symbol systems. Both their status as pictures and their contents are determined by the syntactical and semantic properties they are deemed by common agreement to have." (Goodman, 1968). As Carroll notes, "Goodman reconceptualized the so-called aesthetic response as a cognitive one" (Carroll, 2002).

${ }^{9}$ Another point we should mention here is that universalist and reductionist approaches are also shunned in the art historical canon, as these perspectives are associated with the much-criticised 'white, male, Anglo-Saxon' view (Watling, 1998).
} 
2001, 2003; McMahon, 1999, 2000, 2003; Seeley, 2006) ${ }^{10}$. These scholars use recent results from psychology, vision science and neuroscience to ground various hypotheses on the roots of aesthetics, without being overly reductionistic. Seeley notes that for cognitive theories of aesthetics: "one must distinguish between two uses of the term aesthetics: one that refers to the processes responsible for the perceptual content of artworks, and the other, in a more contemporary sense, refers to what differentiates artworks and aesthetic experiences from their ordinary counterparts. Cognitive science can, at least in principle, explain aesthetics in the former sense. But it is an open question whether it has, as a result, explained aesthetics in the latter sense." (Seeley, 2006).

Art history's criticism of neuroesthetics has not gone unanswered. Zeki, for instance, responds to accusations of 'neuroreductionism' by drawing attention to reductionist tendencies in art historians themselves: after all they separate "sensation from perception, the perceptual from the cognitive and the cognitive from the subjective." (Zeki, 2001). Zeki quotes a passage from Amy Ione's commentory on his work to give an example of what he means under such a seperation:

"[Ione] says that 'we may get a better understanding of how our brains interpret the retinal images our eyes receive". The latter is of course a view of the organization of the visual brain championed by Salomon Henschen and by Paul Flechsig over a century ago, when little was known about the extent and complexity of the visual brain, but it was largely abandoned by visual neurobiologists some thirty years ago. Such statements show the extent to which a dialogue between the art historian and the neurobiologist is necessary. For I would find it difficult to believe that there are many neurobiologists now who would go as far as separating the eye from the brain and the mind when they consider vision as a perceptual process!" (Zeki, 2001).

This passage exemplifies the language barrier between art history and neuroscience. The way Ione formulates the perceptual process of seeing an object in the crudest of terms completely ignores recent vision scientific terminology and discoveries. This is on a par with Ramachandran's dismissal of the contextual aspect of the artwork and of art market's power to judge what is and is not art. The issue is not only a language barrier itself, but a complete unwillingness to overcome it. Obviously, there is a need for a common ground, a catalyst, that works for all the relevant disciplines, so that the language barrier will be naturally and willingly eliminated. We believe that technoscience art offers the right medium to bridge the gap between neuroesthetics and art history, as it uses theories from both cognitive sciences and art history, and reflects on vital questions of both disciplines.

\section{Technoscience Art}

Technoscience Art is a term coined by Frank Popper (Popper, 1987), in an editorial of Leonardo, to cover diverse art practices that involve technological inventions or scientific ideas. As a movement, its history can be traced back to early 1960s, where the first computer-generated artworks were put on display. Today, a plethora of names (information arts, software art, code art, Internet art, robotic art, ambient art) are employed to tag subbranches of technoscience art, simply because the idea of creating artworks at the intersection of arts, technology and sciences is a widespread endeavour that draws on disciplines like computer science, cognitive science, neuroscience, and even nanotechnology.

Technoscience art shows striking similarities to neuroesthetics: both rely on concepts coming from sciences and arts, both try to address a mixed audience that does not share any common backgrounds, and both are disputed by the main art historical circles. During the first decade of the movement, aesthetics was an important research venue for technoscience artists. The combinatorial possibilities offered by the computer lead the artists to create variations of simple geometric patterns, and many possible combinations of a single composition, from which the most aesthetically pleasing ones could be selected. With this approach, philosophers like Max Bense (Bense, 1965) and Abraham Moles (Moles, 1966) pioneered the search for mathematical rules governing aesthetics, and their theories were influential. However, their attempt to legitimize computer generated pictures as true artworks was not very successful, as art criticism was not willing to explore a scientific formula for artistic production. Thus, technoscience art initially received the same reaction that neuroesthetics was to receive several decades later.

A number of developments helped technoscience art to carve itself a niche in the art world. We believe that this progress could itself serve as an example for bridging art history and neuroesthetics. In brief, the technoscience art movement created its own audience, its own specialized theoreticians, and publication venues. Once this infrastructure was in place, the cross-pollination of the disciplines was possible, mainly through scholars who were well-versed in the language of art history, and who learned the necessary scientific terminology to follow up with technoscience art. Neuroesthetics needs precisely this kind of infrastructure now.

Of particular importance is the journal Leonardo, which emphasizes the interaction of arts, sciences and technology, and which offers a fruitful space for exchanging ideas on the latest developments in technology and sciences that are of interest to artists and art critics. The journal has published articles by canonical critics such as Gombrich, Arnheim, and Gibson on the psychological explorations of artworks, as well as works of neuroscientists like Jean Pierre Changeaux on the relation of aesthetics and neurology (Changeux, 1994). Thus, Leonardo provides neuroesthetics with an audience familiar with the earlier theories that link arts to psychology and neurology, in addition to the mathematical explorations of aesthetics. Furthermore, this audience is familiar with the terminology of both art history

\footnotetext{
${ }^{10}$ For a good survey of different theories of vision science and neuroscience that have been used by aestheticians and art historians see (Rollins, 1999).
} 
and neurology in general. It may be argued that the content of these articles does not go deep in either discipline, yet when compared to an ordinary art historian, the readers of Leonardo are surely much more comfortable in following the research in neurosciences and cognitive science.

Aside from serving as a historical example, technoscience art can contribute to art history and neuroesthetics directly through its artworks. Artists in this movement questioned the very nature of artistic production by using computer programs. The most salient example is Harold Cohen's artificial painter program AARON, which has its own coded sense of aesthetics that it uses in conjunction with an understanding of composition to automatically create paintings from scratch.

Harold Cohen is one of the most widely recognized electronic artists, and he let AARON evolve through more than 25 years to its present state of maturity. In his words, AARON was originally "a program designed to investigate the cognitive principles underlying visual representation" (Cohen, 1988). In 25 years of its artificial life, AARON 'learned' to draw, like a child's first scribbles slowly transforming into a modernist painter's stylistic abstractions. The processes developed by AARON to create its paintings can be inspected to discover patterns and clues about 'creativity', but not everyone who watches AARON paint will find sufficient evidence to call it 'creative'. There have been debates about the definition of creativity, and whether it is possible to concede that an artificial intelligence (AI) program can be creative like a painter, or not. ${ }^{11}$

If there are rules or a procedural description for the artistic activity, then there is no reason why a computer program cannot be written to produce art. According to Ramachandran, AARON does precisely this. Furthermore, he justifies this claim by pointing out that the art market pays good prices for AARON's paintings, and that is a sufficient indication that they are real art (though, as seen above, he overlooked such culturally-based criteria in his discussion of cubism). There are two problems with this argument. First of all, even though AARON makes use of some basic principles about the nature of art, these principles are not necessarily universal and Cohen certainly never claimed that they were. His aim was not to search for a set of universal principles, but rather to explore the ideas behind pictorial representation from the point of view of an artist. Thus, AARON works on the preferences of its creator, and draws pictures similar in style to Cohen himself.

The second problem is the fact that a good price is not a sufficient condition for being 'art', and this is obvious to anyone familiar with art history. The fallacy in the argument is the direct result of the language barrier, the lack of a proper definition of 'art,' which is never formulated as concisely as a mathematical formula, but rather involves a lot of intuition and context. Incidentally, the output of AARON is widely accepted as art, but for totally different reasons. First and foremost, it is Harold Cohen that legitimizes AARON's output by being an artist, and by his willingness to exhibit them. Secondly, the art venues that choose to exhibit them (e.g. MOMA) associate an artistic context with these pictures. We must not forget that in today's artistic enterprise, what makes a piece an 'Artwork' is necessarily different than what made it 200 years ago. Ramachandran fails to acknowledge the cultural and political side of AARON's pictures. ${ }^{12}$

On the other hand, AARON proves the possibility of having a particular artistic style captured by a computer algorithm. Whether the principles put forward by Ramachandran and Hirstein (Ramachandran \& Hirstein, 1999) are overlapping with AARON's evolved rules is an interesting question, but if there are a set of rules for universal aeshetics, it is likely to be a superset of both. As a Gedankenexperiment, suppose that this set of rules does exist, and a program is written to create universally pleasing pictures. The output of this program can be considered as art, not because it will be aesthetically pleasing, but because it will have a unique place in the art historical debates on creativity and aesthetics. As the Gedankenexperiment indicates, a better understanding of both art history and neurosciences is necessary to formulate experiments that produce results useful to both disciplines, and the assumptions and arguments used by neurologists do not always reflect an up-to-date understanding of arts. To overcome the language barrier, it is essential that these issues are debated jointly by both parties.

Another technoscience art example that forces its audience to reflect on these issues comes from the curator and artist Ippolito. In his work Trusting Aesthetics to Prosthetics (Ippolito, 1997), he scrutinizes three programs (written by others) in order to establish a new way of defining aesthetic values. The first program is Firefly, which is an Internetbased program that works like a search engine. It learns the musical preferences of its users through a set of music albums that the user has to grade from best to worst. Then the program compares these preferences with the lists of other users, and notifies the user about musicians that are of potential interest, as well as about the new releases of his/her favorites. The preferences of the user are stored by the system, and represent the aesthetic taste of the user. Ippolito calls this set of preferences the 'prosthetic ego' of the user. What the program does is a simple comparison of all prosthetic egos. It does not have a set of pre-established aesthetic values, but nonetheless, it is able to make good suggestions. According to Ippolito, this is a process where the aesthetics is created on the fly, without any judgments or strict rules, where only the subject's position is needed at the first step when the user trains the prosthetic ego: "No one is in charge, and theoretically, no one's taste is more important than any others" (Ippolito, 1997).

The second program, Interactive Genetic Art, works on

\footnotetext{
${ }^{11}$ For a discussion of the creativity of the tools produced by AI in general see e.g. (Tijus, 1988; Carrier, 1986).

${ }^{12}$ Even though art escapes a precise definition in humanities, it is often the case in neuroesthetics that a particular reseach agenda leads to a particular definition of arts. Usually such definitions disregard the conceptual (and thus political and cultural) dimension of arts and focus on visual qualities. One such example claims that "the purpose of art, surely, is not merely to depict or represent reality -for that can be accomplished very easily with a camera- but to enhance, transcend, or indeed even to distort reality." (Ramachandran \& Hirstein, 1999).
} 
assumptions similar to those of the Firefly, but operates with visual input rather than audio. Interactive Genetic Art does not operate over the Internet, but runs on users' computers in a way that resembles the genetic evolution of DNA. In the first 'generation,' the program displays a number of simple forms (e.g. circles, lines, and dots) to the user, and asks the user to evaluate these forms. The user preference acts as the fitness function, and exerts a selective pressure on the forms as the program explores the form space. According to the answers received from the users, the program eliminates the disliked forms from the next generation. In a few generations, the program moves on to much more complex shapes, and eventually to compositions and artworks.

The third program considered by Ippolito is Tierra, which was written by the evolutionary biologist Tom Ray (Ray, 1992). It is one of the forerunners of artificial life (A-life) programs, and simulates artificial life forms, which are a collection of programs that reside in computers memory. These try to create copies of themselves, thereby competing with each other for a scarce resource, i.e. memory. Writing short programs that duplicate themselves has been an old challenge for computer programmers. Tierra is able to evolve programs that are shorter and more efficient in duplicating themselves than programs created by experienced programmers. Moreover, there appear virus-like programs that lack a replication mechanism, and consequently are very short. These programs can harness the replication mechanisms of other programs in the memory. In some generations, these programs dominate the memory, but as the programs on which they rely for replication get scarcer, they fail to replicate themselves. Non-linear dynamics similar to actual evolution in a natural environment emerge, and niching behaviour is observed. For Ippolito, Tierra turns into an aesthetic-evolution machine. He proposes to apply Tierra to estimate aesthetic judgments by running it to evolve programs with prosthetic egos of their own, without any input from user's preferences. The idea is that small programs that have never been in touch with the aesthetic and social criteria of the academy, aestheticians and art historians stand a chance of creating an evaluation system that is not tainted by an abject subjectivity.

These examples demonstrate that art created with a deeper understanding of science, technology and art theories brings about a perspective that easily questions the assumptions derived from any single disciplinary knowledge and the surrounding culture. Art historians and neuroscientists have different preconceptions about the definition of art. One of the basic assumptions of art history is that art objects stipulate a certain feeling/condition that other objects cannot evoke (Preziosi, 1989). Neuroesthetics is based on a variation of this preconception, it assumes that this feeling is universal and that it is possible to quantify and measure this condition with the help of latest technological apparatus and through scientific experimentation. This is relevant for neuroscience particularly for the reason that if the emergent properties of human aesthetics could be dissociated from the cultural baggage and be studied on their own, they could provide insights to the workings of the brain. Neuroesthetics takes it for granted that aesthetic judgment is an innate fac- ulty of man, yet artists like Ippolito question even this deeply ingrained idea of art history by taking the human out of the picture.

Our last example is an artwork that is neither created for the usual art market, nor to call for theoretical debates or to criticize the bare assumptions around the discourse of art and art history. It consists of a simple suggestion that immediately pushes on the boundaries of art as an enterprise. The idea is straightforward: take a white, ordinary ping pong ball, cut it into two halves, and lie down under a tree on a sunny day with these half-balls covering your eyes. The experience is a homogenous fog-like opaque white colour (called ganzfeld) that has no equivalent sensation in any everyday environment. This fog will eventually create interesting sensations, as the mind tries to cope with the lack of information in the visual stimuli. In this special setting designed by Scott Daly, the environment is projected by the shadows of the trees, clouds and objects around the subject, and adds a soothing feeling to the ganzfeld sensation.

Ganzfeld is a neurophysiological phenomenon first defined by the German psychologist W. Metzger in 1930, and often used in parapsychology experiments (Palmer, 2003). A person in the ganzfeld receives very little visual stimuli, and Daly argues that what the person perceives is the 'perceptual process itself' (Daly, 1984). In proposing the ping pong ball experiment as an artwork, Daly wanted to explore the entoptic phenomena. These are perceptions generated within the visual system, like experiencing afterimage affects after holding your hands on your eyes, or like seeing tiny little dots after looking at sky for a long period of time. Daly was excited at the idea of creating an art object, or rather an art idea, which directly stimulated the brain, and made the viewer aware of his/her own perception process: "the ganzfeld, like dreams, is a medium we reside within; external influence is minimal. The ganzfeld is simultaneously a mode for artwork to occur within us, rather than to occur as a specific object."(Daly, 1984). ${ }^{13}$

The creative ideas put forward by artists can open up new research venues for neuroscience and neuroesthetics. In an interview for one of the earliest technoscience art exhibitions (Cybernetic Serendipity, held in 1968), Charles Csuri suggested using brain waves for drawing. He gave a deliberate and detailed plan of the experimental setup, and hyphothesized that if one could record and digitize brain waves, they could be transferred to the computer; subsequently one could command the computer to draw by only thinking about the drawing itself. Csuri explained in detail how such a device could be produced, and how a trained artist might get the computer to draw basic geometrical shapes. The "training' Csuri had in mind is actually a cristallization of the thought process to such a degree that the mere thought of the

${ }^{13}$ Daly is by no means the first artist who is interested in the effects of extraordinary stimuli. As early as 1972, Baldwin experimented with similar visual stimuli while creating his kinetic artworks. He conducted experiments with photic-stimulation of alpha brain waves to explore the subliminal stimulation of visual perception (R. Baldwin, 1972; R. B. Baldwin, 1974). 
shape results in a sufficiently expressive wave length, and allows an unambiguous interpretation by the computer (Efland, 1968). ${ }^{14}$ This idea was futuristic for its time, yet today research on brain-computer interfaces report the possibility of such interactions with computers, primarily intended for people with disabilities (Wolpaw, Birbaumer, McFarland, Pfurtscheller, \& Vaughan, 2002).

The possibility of freeing the communication between the artist and the audience from the necessity of representation makes research into neurology of the brain very appealing to artists. Peter Weibel puts forth one attempt to resolve what he has termed the crisis of representation. Weibel argues that technology is shaped by the prevailing sciences of its time. For an example, he relates the birth of cinema to the scientific understanding of $19^{\text {th }}$ century. In a brief survey on the history of pre-cinema years, Weibel points out to discoveries of physiology (e.g. optical illusions, and the laziness of the eye), which eventually are translated into technology as the motion-machine (i.e. cinematic apparatus). It follows that the technology of the future will be based on the scientific thinking of the $20^{\text {th }}$ century. For him, the important paradigm shift in this century is the cybernetic understanding of machines, whose functionality can be dissected into three vital properties: machines that are able to simulate perceptual processing, machines with receptors and effectors ${ }^{15}$, and finally machines that simulate thinking (Weibel, 2003).

The real breakthrough occurs when we start thinking of the image as a system, and try to achieve a resolution for this system that will solve the problem of representation. According to Weibel, who calls such an image as the Intellectual Image, we can achieve the solution if we operate on the resolution of neurons. This idea forms the basis of a future cinema, a sort of neuro-cinema. Thus, the technoscience artist wants to go beyond present interfaces, and have neuronal interfaces ${ }^{16}$ that are based on neuronal information theory, in which non-hierarchical, decentralized structures (like the Internet) are employed. In a sense, this is Csuri's futuristic view of producing artworks that are directly conveyed to the brain of the audience, without the taint of an intermediate medium. That is the artists' challenge for the neuroscientist.

\section{Conclusion}

In this paper we draw attention to problems created by the language barrier between art history and neuroesthetics, and propose technoscience art as a venue that stands the chance of bridging the gap between these disciplines. Interdisciplinary research areas like neuroesthetics often face the problem of addressing audiences of diverse backgrounds, which manifests itself through the lack of a common technology and different research concerns. In the case of art history and neuroesthetics, there is the added complication introduced by the paradigmatic differences between science and humanities. In particular, key concepts like arts, aesthetics, and representation do not have concrete definitions that can provide a solid ground for empirical research.

In this context, technoscience art may serve a two-fold purpose. First and foremost, it can provide a collaborative setting that fosters individuals competent in both areas. Indeed, the need for collaboration lies at the core of technoscience art, as the first artworks of the genre were born out of joint efforts of innovative artists and scientists with access to computers that were so rare at the time. Grounded in this legacy, technoscience artworks call for an interdisciplinary terminology. Examples given in the last section demonstrate that such works indeed push the boundaries of research by questioning the unquestioned and challenging the assumptions, which is the second contribution of technoscience art.

Neuroesthetics suffers from a lack of understanding pertaining to the relevant issues of the art historical agenda, and a neglect of cultural and social dimensions that are crucial for art history. Consequently, its research questions are of limited relevance for art historians. Another problem of neuroesthetics is that it is almost completely confined to visual stimuli, whereas aesthetic judgements permeate all domains of experience. On the other hand, art history is plagued by an unfounded fear of reductionism with regards to neuroesthetics. This is a direct consequence of the lack of a common ground between the disciplines, which this paper aims to alleviate to a certain degree.

\section{Acknowledgments}

The authors would like to thank John Hunter, Angelica Afanador Pujol, and Bürkem Cevher for their valuable comments.

\section{References}

Arnheim, R. (1956). Art and Visual Perception; A Psychology Of The Creative Eye. Faber and Faber.

Arnheim, R. (1969). Visual Thinking. University of California Press.

Baldwin, R. (1972). Kinetic art: On producing illusions by photicstimulation of alpha brain waves with flashing lights. Leonardo, 5(2), 147-149.

Baldwin, R. B. (1974). Kinetic art: On the use of subliminal stimulation of visual perception. Leonardo, 7(1), 1-5.

Baumgarten, A. (1954). Reflections on Poetry; Alexander Gottlieb Baumgarten's Meditationes Philosophicae de Nonnullis Ad Poema Pertinentibus. University of California Press.

Bense, M. (1965). Aesthetica: Einführung in die neue Aesthetik. Agis-Verlag.

Bentivoglio, M. (2003). Musical Skills and Neural Functions: The Legacy of the Brains of Musicians. Annals of the New York Academy of Sciences, 999(1), 234.

Bogousslavsky, J. (2003). The Neurology of Art-The Example of Giorgio de Chirico. European Neurology, 50(4), 189-190.

${ }^{14}$ In 1972, four years after Csuri's proposal, Rosenboom tried to make use of EEG monitoring to have his subjects consciously control the production of sounds (Rosenboom, 1972).

${ }^{15}$ Receptors help the machine to collect information from the environment, and effectors put information into the environment, thus establishing a feedback loop. In computer science and robotics, the more common terminology refers to sensors and actuators, respectively.

${ }^{16}$ See (Wolpaw et al., 2002) for a recent study on brain and computer interfaces. 
Carrier, D. (1986). Theoretical perspectives on the arts, sciences and technology. Leonardo, 19(1), 77-80.

Carroll, N. (1986). Art and Interaction. The Journal of Aesthetics and Art Criticism, 45(1), 57-68.

Carroll, N. (2002). Aesthetic Experience Revisited. The British Journal of Aesthetics, 42(2), 145-168.

Changeux, J.-P. (1994). Art and neuroscience. Leonardo, 27(3), 189-201.

Cohen, H. (1988). How to Draw Three People in a Botanical Garden. Proceedings of the Seventh National Conference on Artificial Intelligence, 846-855.

Cupchik, G. C. (1994). Emotion in aesthetics: Reactive and reflective models. Poetics, 23, 177-188.

Daly, S. (1984). The ganzfeld as a canvas for neurophysiologically based artworks. Leonardo, 17(3), 172-175.

Danto, A. (2001). The Madonna of the Future. In (chap. Art and Meaning). University of California Press.

Dixon, R. (1995). The Baumgarten corruption: from sense to nonsense in art and philosophy. Pluto Press.

Efland, A. (1968). An Interview with Charles Csuri. Studio International, special issue: Cybernetic Serendipity: the computer and the arts(July), 81-84.

Freedberg, D., \& Gallese, V. (2007). Motion, emotion and empathy in esthetic experience. Trends in Cognitive Sciences, 11(5), 197-203.

Goodman, N. (1968). Language of Art. NY: The Bobbs-Merill Co.

Hammermeister, K. (2002). The German Aesthetic Tradition. Cambridge University Press.

Ippolito, J. (1997). Trusting Aesthetics to Prosthetics. Art Journal, 56(3).

Kandel, E., \& Mack, S. (2003). A Parallel Between Radical Reductionism in Science and in Art. Annals of the New York Academy of Sciences, 1001(1), 272.

Kawabata, H., \& Zeki, S. (2004). Neural Correlates of Beauty. Journal of Neurophysiology, 91(4), 1699-1705.

Lakoff, G. (2006). The Neuroscience of Form in Art. The Artful Mind: Cognitive Science and the Riddle of Human Creativity.

McMahon, J. (1999). Towards a Unified Theory of Beauty. Literature and Aesthetics, 9, 7-27.

McMahon, J. (2000). Perceptual Principles as the Basis for Genuine Judgments of Beauty. Journal of Consciousness Studies, 7(8-9), 29-35.

McMahon, J. (2003). Perceptual Constraints and Perceptual Schemata: The Possibility of Perceptual Style. The Journal of Aesthetics and Art Criticism, 61(3), 259-272.

Mendez, M. (2004). Dementia as a window to the neurology of art. Medical Hypotheses, 63(1), 1-7.

Moles, A. (1966). Information Theory and Esthetic Perception. University of Illinois Press

Otte, A., De Bondt, P., Wiele, C. Van de, Audenaert, K., \& Dierckx, R. (2003). The exceptional brain of Maurice Ravel. Medical Science Monitor, 9(6), 154-159.

Palmer, J. (2003). ESP in the Ganzfeld. Journal of Consciousness Studies, 10(6-7).

Popper, F. (1987). Editorial: Technoscience art: The next step. Leonardo, 20(4), 301-303.

Preziosi, D. (1989). Rethinking Art History: Meditations on a Coy Science. Yale University Press.
Ramachandran, V. (2001). Sharpening up the "science of art": An Interview with Anthony Freeman. Journal of Consciousness Studies, 8(1), 9-29.

Ramachandran, V., \& Hirstein, W. (1999). The science of art. Journal of Consciousness Studies, 6(6-7), 15-41.

Ravin, J., \& Ravin, T. (1999). What Ailed Goya? Survey of Ophthalmology, 44(2), 163-170.

Ray, T. (1992). Evolution, ecology and optimization of digital organisms.

Rollins, M. (1999). Pictorial representation: when cognitive science meets aesthetics. Philosophical Psychology, 12(4), 387-413.

Rollins, M. (2001). The Invisible Content of Visual Art. The Journal of Aesthetics and Art Criticism, 59(1), 19-27.

Rollins, M. (2003). The Mind in Pictures: Perceptual Strategies and the Interpretation of Visual Art. The Monist, 86(4), 608-632.

Rolls, E. (2000). The Orbitofrontal Cortex and Reward. Cerebral Cortex, 10(3), 284-294.

Rosenboom, D. (1972). Method for producing sounds or light flashes with alpha brain waves for artistic purposes. Leonardo, 5(2), 141-145.

Sahlas, D. (2003). Dementia With Lewy Bodies and the Neurobehavioral Decline of Mervyn Peake (Vol. 60) (No. 6). Am Med Assoc.

Seeley, W. (2006). Naturalizing aesthetics: art and the cognitive neuroscience of vision. Journal of Visual Art Practice, 5(3).

Silvia, P. (2005). Emotional responses to art: From collation and arousal to cognition and emotion. Review of general psychology, 9(4), 342-357.

Spence, C., \& Driver, J. (2004). Crossmodal Space and Crossmodal Attention. Oxford University Press.

Stafford, B. (2004). Romantic Systematics and the Genealogy of Thought: The Formal Roots of a Cognitive History of Images. Configurations, 12, 315-348.

Stewart, E. (2002). de Kooning's dementia. Am J Alzheimers Dis Other Demen, 17(5), 313-7.

Tijus, C. (1988). Cognitive Processes in Artistic Creation: Toward the Realization of a Creative Machine. Leonardo, 21(2), 167172.

Watling, C. (1998). The Arts, Emotion, and Current Research in Neuroscience. Mosaic (Winnipeg), 31(1).

Weibel, P. (2003). Future cinema: The cinematic imaginary after cinema. In S. Jeffrey \& W. Peter (Eds.), (chap. The Intelligent Image: Neurocinema or Quantum Cinema). MIT Press.

Wessell Jr, L. (1972). Alexander Baumgarten's Contribution to the Development of Aesthetics. The Journal of Aesthetics and Art Criticism, 30(3), 333-342.

Wolpaw, J., Birbaumer, N., McFarland, D., Pfurtscheller, G., \& Vaughan, T. (2002). Brain-computer interfaces for communication and control. Clinical Neurophysiology, 113(6), 767-791.

Zeki, S. (1999). Inner vision: an exploration of art and the brain. Oxford University Press.

Zeki, S. (2001). Closet reductionists. Trends in Cognitive Sciences, $5(2), 45-46$.

Zeki, S. (2004). Neural Concept Formation and Art: Dante, Michelangelo, Wagner. Neurology of the Arts: Painting, Music, Literature

Zeki, S., \& Lamb, M. (1994). The neurology of kinetic art. Brain, 117(Pt 3), 607-36. 